\title{
A complex variation of the digastric muscle: a case report
}

\author{
Özdemir Sevinç ${ }^{1}$, Z. Aslıhan Çetin ${ }^{2}$, Çağatay Barut ${ }^{3}$, Bora Büken ${ }^{4}$, Yasin Arifoğlu ${ }^{5}$ \\ ${ }^{1}$ Department of Anatomy, School of Medicine, Çanakkale Onsekiz Mart University, Çanakkale, Turkey \\ ${ }^{2}$ Department of Anatomy, School of Medicine, Diizce University, Diizce, Turkey \\ ${ }^{3}$ Department of Anatomy, School of Medicine, Zonguldak Karaelmas University, Zonguldak, Turkey \\ ${ }^{4}$ Department of Forensic Science, School of Medicine, Diizce University, Diizce, Turkey \\ 'Department of Anatomy, Izzet Baysal School of Medicine, Abant İzzet Baysal University, Bolu, Turkey
}

\begin{abstract}
The anterior belly of the digastric muscle varies greatly in its shape and size. It is important to know the variations of the digastric muscle, as it is used as a landmark in certain surgical procedures. A complex variation of the digastric muscles was detected during the routine dissection of a 55-year-old male cadaver. The anterior belly of the digastric muscle on the left side had an accessory bundle, which arose from the anterior part of the intermediate tendon and divided into two parts after a 2-cm course. The superior part coursed toward the mylohyoid raphe and fused with the mylohyoid muscles of both sides. The inferior part travelled parallel to the hyoid bone and fused with the right mylohyoid muscle. Another accessory bundle was found between the origin of the anterior belly of the right digastric muscle and the bifurcation site of the aforementioned bundle. This latter accessory bundle had no attachment to the mylohyoid muscle. Knowledge of the variations of the digastric muscles may prevent complications when surgery is performed in the suprahyoid region or when imaging is interpreted for this region.
\end{abstract}

Key words: digastric muscle; anterior belly; variation; intermediate tendon

Anatomy 2009: 72-74, @ 2009 TSACA

\section{Introduction}

The mylohyoid, geniohyoid, stylohyoid, and digastric muscles are regarded as suprahyoid muscles. The digastric muscle has two bellies joined by an intermediate tendon that is anchored to the hyoid bone. The posterior belly originates from the medial side of the mastoid process of the temporal bone and travels downward and forward to the hyoid bone. The anterior belly is attached to the digastric fossa near the midline and runs downward and backward to the hyoid bone. The two bellies meet at an intermediate tendon. ${ }^{1}$ The anterior bellies form the lateral boundaries of the submental triangle with the hyoid bone as the base. ${ }^{2}$ The contents of the submental triangle include various amounts of adipose tissue and lymph nodes, as well as several anterior communicating vessels. ${ }^{2-4}$

Several studies have described the variations of the anterior bellies of the digastric muscles. It is generally agreed that the digastric muscle stabilizes and regulates the position of the hyoid bone and assists in jaw movements, primarily in depressing the mandible..$^{5-9}$ Anatomical variations in the digastric muscle may affect diagnostic and therapeutic procedures. This study demonstrates a bilateral anomaly of the anterior bellies of the digastric muscles, which is of clinical interest with surgery or imaging of this region. 


\section{Case Report}

A complex variation of the digastric muscles was detected during the routine dissection of a 55-year-old male cadaver. The anterior belly of the digastric muscle was found to have an accessory bundle on the left side. This accessory bundle arose from the anterior part of the intermediate tendon and divided into two parts after a 2$\mathrm{cm}$ course. The superior part was directed toward the mylohyoid raphe and fused to the mylohyoid muscles on both sides. The inferior part was parallel to the hyoid bone and fused to the right mylohyoid muscle. In addition, another accessory bundle was located between the origin of the anterior belly of the right digastric muscle and the bifurcation site of the aforementioned bundle. This accessory bundle had no attachment to the mylohyoid muscle. The posterior bellies of the digastric muscles were normal on both sides (Figure 1).

\section{Discussion}

Anomalies of the digastric muscles are common. ${ }^{10,11}$ Holibkova and Machalek ${ }^{12}$ reported two anomalies of the anterior bellies of digastric muscles. Connell and Shamoun ${ }^{3}$ encountered excess digastric muscle bulk in several cases, observing that the large digastric muscle became apparent, bulging through the overlying platysma, when the patient was lying in the supine position with the head flexed. Turan-Özdemir et al. ${ }^{4}$ observed accessory muscle bundles of the anterior bellies of the digastric muscles on both sides. Aktekin et al. ${ }^{13}$ reported bilateral and symmetrical variation of the anterior belly of the digastric muscle. Çelik et al. ${ }^{7}$ reported that the anterior belly of the left digastric muscle had four separate insertions to an ipsilaterally enlarged digastric fossa. Sargon and Çelik ${ }^{10}$ found a digastric muscle with three bellies on the right. Akkın and Özkuş ${ }^{14}$ reported variations of the anterior belly of the digastric muscles in two cases. Their first case had two accessory bellies on both sides, both of which inserted into the right side, whereas the second case had five-segmented anterior belly. ${ }^{14}$ Several other studies have demonstrated variations of the anterior bellies and the fibrous sling of the digastric muscle. $^{6,15}$

An accessory mylohyoid muscle arising from the left mylohyoid line of the mandible and inserting between the caudal part of the median fibrous raphe of the mylohyoid muscle and hyoid bone has also been reported. ${ }^{11}$ Şehirli and Çavdar ${ }^{11}$ suggested that this anomaly is a very rare and important case related to the function of the muscular floor of the oral cavity. The anterior belly of the digastric develops from the mandibular prominence

Figure 1. Submental region showing digastric muscles (inferior view). A: Accessory bundle of the anterior belly of the digastric muscle which arose from the intermediate tendon; 1: Superior part; 2: Inferior part; $A^{\prime}$ : Other accessory bundle located between the origin of the anterior belly of the right digastric muscle and the bifurcation site of $A$.

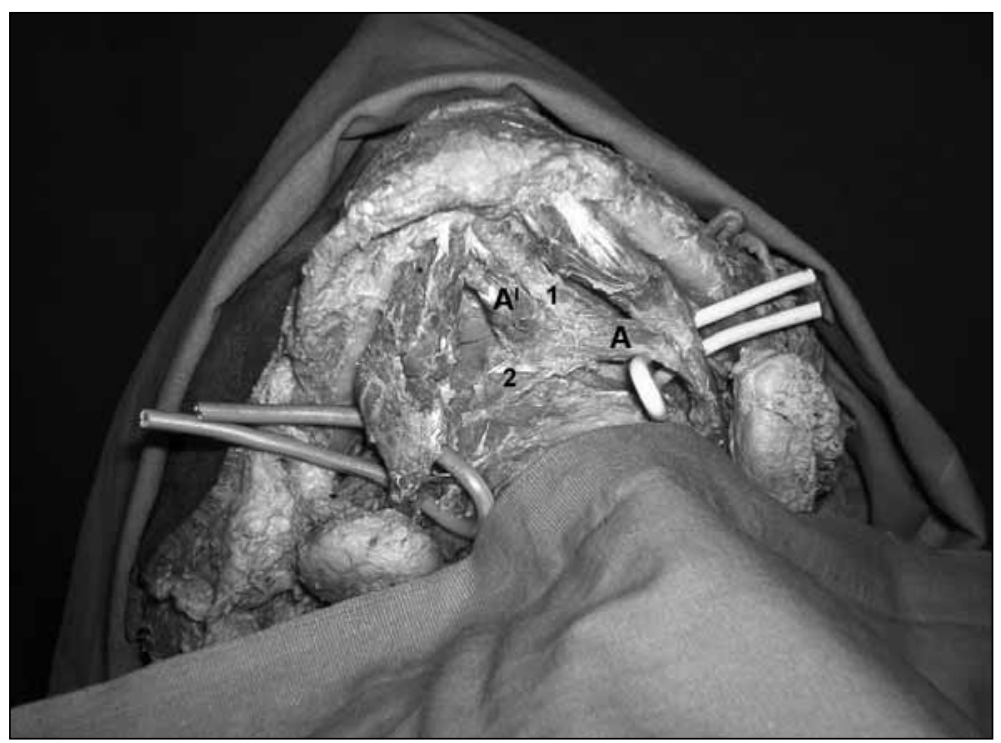


(the ventral part of the first branchial arch), which grows ventromedially to meet its fellow in the midline. Although the fusion of the anterior digastric with the mylohyoid muscle may be attributed to their common embryological origin, ${ }^{1,16,17}$ Akkın and Özkuş ${ }^{14}$ found no relation between the accessory anterior bellies and the mylohyoid muscle.

MRI and CT are equally good modalities for evaluating anatomical and pathological lesions of the floor of the mouth, and both guide the planning and extent of surgical resection. ${ }^{18}$ Variations of the anterior bellies of the digastric muscles can also be detected by these imaging modalities. ${ }^{2}$ Bilateral symmetry is an important criterion in the radiological evaluation of the submental region. ${ }^{4}$ The lymphatic drainage from the floor of the mouth and sublingual salivary glands is via the submental nodes in the submental triangle. Both inflammatory lesions and metastases from malignant lesions of this area will cause enlargement of these lymph nodes. Muscle enlargement and asymmetry can be caused by tumor invasion, which can be seen on CT as an increase in the bulk of the muscle, accompanied by contrast enhancement of the same muscle. ${ }^{2}$ An accessory digastric muscle, crossing the submental triangle muscles, can be easily confused with a pathological condition, such as a tumor or enlarged lymph nodes on CT or MR examination. ${ }^{4}$ For this reason, knowledge of the muscular anatomy and its variations is helpful when evaluating this region.

\section{References}

1. Williams PL, Warwick R, Dyson M, Bannister LH. Gray's Anatomy. 37th ed. New York: Churchill Livingstone; 1989.

2. Larsson SA, Lufkin GB. Anomalies of digastric muscles: CT and MR demonstration. 7 Comput Assist Tomogr 1987; 11: 422-5.
3. Connell BF, Shamoun JM. The significance of digastric muscle contouring for rejuvenation of the submental area of the face. Plast Reconstr Surg 1997; 99: 1586-90.

4. Turan-Özdemir S, Oygucu İH, Kafa İM. Bilateral abnormal anterior bellies of digastric muscles. Anat Sci Int 2004; 79: 95-7.

5. Plesh O, Bishop B, Mc Call WD. Patterns of jaw muscle activity during voluntary chewing. 7 Oral Rehabil 1996; 23: 262-9.

6. Peker T, Turgut HB, Anıl A. Bilateral anomaly of anterior bellies of digastric muscles. Surg Radiol Anat 2000; 22: 119-21.

7. Çelik HH, Aldur MM, Özdemir B, Akşit MD. Abnormal digastric muscle with unilateral quadrification of the anterior belly. Clin Anat 2002; 15: 32-4.

8. Willigen JDV, Broekhuijsen ML, Melchior HJ, Karkazis HC, Kossioni A, Heath MR. Digastric muscle response as a function of knowledge of the task to be performed. Arch Oral Biol 1993; 38: 113-21.

9. Karkazis HC, Kossioni A, Heath MR, Willigen JDV. Anterior digastric muscle responses to sudden unloading of the mandibular elevator muscles in younger and older adults. 7 Oral Rehabil 1993; 20: 433-9.

10. Sargon MF, Çelik HH. An abnormal digastric muscle with three bellies. Surg Radiol Anat 1994; 16: 215-6.

11. Şehirli Ü, Çavdar S. An accessory mylohyoid muscle. Surg Radiol Anat 1996; 18: 57-9.

12. Holibkova A, Machalek L. A report on anomalies of digastric muscle. Acta Univ Palacki Olomuc Fac Med 1999; 142: 57-9.

13. Aktekin M, Kurtoğlu Z, Öztürk AH. A bilateral and symmetrical variation of the anterior belly of the digastric muscle. Acta Med Okayama 2003; 57: 205-7.

14. Akkın SM, Özkuş K. M. digastricus'un venter anterior varyasyonlarının değerlendirilmesi. Çukurova Üniversitesi Tip Fakiiltesi Dergisi 1992; 17: 248-55.

15. Sarıkçığlu L, Demir S, Oğuz N, Sindel M. An abnormal digastric muscle with three accessory bellies and one fibrous band. Surg Radiol Anat 1998; 20: 453-4.

16. Sadler T. Langman's Medical Embryology. 5th ed. Baltimore: Williams \& Wilkins; 1985.

17. Moore KL. The Developing Human: Clinically Oriented Embryology. 4th ed. Philadelphia: WB Saunders; 1988.

18. Mast HL, Haller JO, Solomon M. Benign lesions of the mandibular and maxillary region in children: characterization by CT and MRI. Comp Med Imag Graph 1992; 16: 1-9.

Correspondence to: Dr. Çağatay Barut, MD, PhD

Department of Anatomy

School of Medicine, Karaelmas University

Zonguldak 67600 Turkey

Phone: +90 53246384 71; Fax: +903722610264

e-mail: cagbarut@yahoo.com

Conflict of interest statement: No conflicts declared. 